УДК 130.2

DOI 10.18413/2712-746X-2020-44-2-376-384

\title{
Трансформация культурных практик обмена
}

\author{
Серостанова О.Б. \\ Луганский национальный университет имени Тараса Шевченко \\ Украина, 91011, г. Луганск, ул. Оборонная, 2 \\ E-mail: oxanaserostanova@gmail.com
}

\begin{abstract}
Аннотация. Культура XXI века стремительно изменяет сферу взаимоотношений людей и практику их самовыражения. Автором предпринята попытка определить содержательную основу символического обмена в культуре информационного общества. Проведен анализ понятия культурно-символического обмена с позиций философии постмодерна, символического интеракционизма, структурной антропологии, коммуникативного и мир-системного подхода. В качестве системообразующего компонента общественных отношений исследуется эвристический потенциал имиджевой коммуникации в условиях культуры постмодерна. Совокупность ее знаковых воплощений формирует смысловое поле общения между людьми. Продолжает оставаться дискуссионным вопрос о принципах обмена в пространстве реальных и виртуальных коммуникативных практик.
\end{abstract}

Ключевые слова: символический обмен, смысловое поле, коммуникация, трансформация, мифологизация, фрагментация, массмедиа, симулякр.

Для цитирования: Серостанова О.Б. 2020. Трансформация культурных практик обмена. NOMOTHETIKA: Философия. Социология. Право. 45 (2): 376-384. DOI 10.18413/2712-746X-202044-2-376-384

\section{Transformation of cultural practices of exchange}

\author{
Oksana B. Serostanova \\ Luhansk Taras Shevchenko national University, \\ 2 Oboronnaya St, Lugansk, 91011, Ukraine \\ E-mail: oxanaserostanova@gmail.com
}

\begin{abstract}
Summery. The culture of the XXI century is rapidly changing the sphere of human relationships and the practice of their self-expression. The gap between the social and cultural component of being leads to a sense of "otherness". In order to create and create cultural images, the man of our time must acquire the gift. The culture of gift as a symbolic practice of exchange in archaic societies is reflected in the postmodern. It is connected with the search for new forms of exchange in virtual reality. The article attempts to determine the content basis of symbolic exchange in the culture of the information society. The author analyzes the views on the understanding of symbolic exchange from the positions of postmodern philosophy, anthropology philosophy, symbolic interactionism, structural anthropology of the communicative and world-system approach. The concept of cultural and symbolic exchange on the example of image communication is substantiated. The totality of its iconic incarnations forms the semantic field of communication between people. The issue of the principles of exchange in the space of real and virtual communication practices continues to be debatable.
\end{abstract}

Keywords: symbolic exchange, semantic field, communication, transformation, mythologization, fragmentation, mass media, simulacrum. 
For citation: Serostanova O.B. 2020. Transformation of cultural practices of exchange. NOMOTHETIKA: Philosophy. Sociology. Law series. 45 (2): 376-384 (in Russian). DOI 10.18413/2712-746X-2020-44-2-376-384

\section{Введение}

В процессе поиска понимания культуры и общества XXI века коммуникация становится главным предметом исследования. Возможности ее постижения в качестве координирующего и управленческого посредника человеческих взаимоотношений приводят к постановке вопроса о природе обмена знаками как основы для формирования символического пространства культуры.

В настоящий момент сложившееся представление о культурно-символическом обмене в русле культурфилософского подхода не имеет четкого онтологического статуса, в связи с чем отсутствует целостное представление о данном понятии. Стоит отметить, что оно рассматривается преимущественно в социально-экономическом и бихевиористическом русле. В частности, как таковой самодостаточный исследовательский предмет обмен находит отражение в теории социального обмена, в связи с чем возникает естественный исследовательский интерес в выявлении потенциала культурно-символического обмена в условиях преобразования пространства культуры.

Современный мир, активно применяя информационно-коммуникативные технологии, ориентирован, прежде всего, на воспроизводство нематериальных форм знаков. Развитие новых массмедиа способствуют медиатизации культурной среды, порождающей многочисленные идеи и бренды нашего времени, которые впоследствии наполняют медиапространство новыми символами. Обращает на себя внимание изменение содержательной функции знака, выступающего эквивалентом замещения предмета, свойства, отношения. Призванный обеспечивать трансляцию социокультурного опыта человека в культуре постмодерна, знак утрачивает способность к созданию символического поля ценностей. С теоретической позиции важно понять, каким образом этот процесс взаимосвязан с преобразованием культурных практик обмена. Обратимся к истории исследования этого вопроса.

\section{Традиции понимания культурно-символического обмена}

1. Структурная антропология. Первоначально, в архаических обществах существовала традиция ритуального обмена в форме потлача и жертвоприношений. Они рассматриваются в качестве явлений человеческой культуры, способных дать понимание духовной, сакральной сущности обмена. К. Леви-Стросс рассматривает культурный обмен в контексте понятий родства и языка. Родство является динамическим явлением и предполагает постоянный дар женщинами из поколения в поколение, чтобы поддерживать систему в равновесии [Леви-Стросс, 2001]. Система родства выступает своеобразным языком, имеющим различные аспекты интерпретации. Она зависит от уровня и характера культуры. В данном процессе задействован принцип авункулату, - элемент структуры, состоящий через определенные отношения между членами отношений, атом родства [ЛевиСтросс, 2001, с. 56].

2. Системный подход. Т. Парсонс, анализируя структурные и функциональные изменения в обществе, определяет обмен с позиции элемента системно-интегративного характера. Его задача заключается в равновесии социума в процессе воспроизводства: «...закономерности существования индивидов в социальной системе, предупреждают ее от нестабильности и конфликтов, или придают ей социально-одобренного характера» [Парсонс, 1998, с. 21]. Структурные изменения, предусматривающие создание сетей дружеских связей, возникновение неравенства, выделение институтов (государство, религия, право, мораль, и т.п.), - все это происходит благодаря обменным процессам, распределению мобильных ресурсов, потреблению и присвоению [Парсонс, 1998, с. 28]. 
Многогранные структуры отношений (кооперативные, договорные и т. п.) повышали адаптационные возможности системы.

До промышленной революции, обменные отношения имели локализованный характер. С началом эпохи великих географических открытий, они распространяются на большие расстояния. Их главной задачей становятся регулирование возможностей вступления в контакты с другими культурами. Свобода системы и заморская экспансия Англии, взаимодополняют друг друга в процессе развития коммуникативных матриц обмена. Это сопровождается закреплением принципа единства и многообразия, вознаграждения и ассоциации при осуществлении обменных связей, легитимации и институционализации новых норм и ценностей [Парсонс, 1998].

В таком контексте культурная практика обмена воспринимается как часть культурной системы с присущей ей интегративной способностью. Информационное назначения обменных отношений включает формирование нового полисистемного образования, где главная роль будет принадлежать социальным связям и ценностным потокам.

В средневековье нашла распространение практика индульгенции в аспекте замещения денег в обмен на духовное отпущение грехов. «Монета звенит в ящике, душа вылетает из Чистилища», - так звучит основной постулат церкви периода Реформации. Происходит переоценка принципов обмена в сторону определения их стоимостного эквивалента в виде денег. Впоследствии поддержка католической церковью и Папой Римским 95 тезисов Мартина Лютера привела к расколу в церкви. В данном документальном источнике отражалась информация о действенность индульгенции.

3. Философия постмодернизма. Для культуры постмодерна характерно понимание обмена через смену симулякров. Процесс изменений подразумевал нарушение существующей структуры отношений в условиях сосуществования человека в реальной и воображаемой реальности. В основании симулякров каждого порядка были заложены принципы: естественные законы ценности, рыночные законы стоимости и «чисто структурная игра ценности» [Бодрийяр, 2000, с. 52]. В случае иррациональной реальности обмен мнимыми знаками осуществлялся благодаря постижению истории человечества и его культурного наследия.

«Воображаемое» становится полноценным наряду с «реальным». Его порождают не только цифровые технологии, но и изменение отношения к характеру коммуникации. Последняя воспринимается как динамичная интеллектуальная данность, обладающая интерактивностью и многоканальностью. Нельзя не согласиться с идеей Ж. Бодрийяра о том, что эстетизация мира и его космополитическое инсценирование достигается благодаря массмедиа [Бодрийяр, 2000, с. 25]. Они влияют на сферу человеческих отношений, традиции, историю, искусство и т. п.

Посредством символической деятельности человека продукты идеального и материального вплетаются в мир повседневности. Символический обмен охватывает культурное пространство социума и отражает непрерывную динамику глобальных структур отношений. Коммуникация рассматривается в потоке фетишей, воплощенных в предметной форме в виде товаров, денег, символов, знаков, языка, идей, бренда, имиджа и т.п. Они часто базируются на стереотипах и устоявшихся утверждений, свойственных той или иной культуре. Создается коммуникативная среда. Основываясь на обмене символами, в искусственно сознанной культурной и виртуальной реальности действующие субъекты создают свое представление о происходящем.

В условиях тотального потребления современное искусство выступает ритуализированной практикой. Воспроизводя себя в процессе всеобщей симуляции, человек своими действиями порождает и клонирует симулякры. Копии вещей заполняют символическое пространство человека, имитируя обмен. Однако это не приводит к кумуляции культурных образцов.

Симулякрами могут выступать как бессмысленные знаки, так и знаки, несущие в себе искаженное представление. В целом они формируют смысловое поле коммуникации. 
4. Коммуникативный подход. По мнению Г.Б. Гутнера, поле смыслов являются «совокупностью обсуждаемых и постигаемых предметов» [Гутнер, 2012, с. 431]. Человек находясь одновременно в рациональном, иррациональном и виртуальном пространстве, конструирует взаимоотношения с другими посредством медиаобразов.

Исходя из вышеизложенных представлений, культурно-символический обмен представляет собой совокупность коммуникативных практик, функционирующих по принципу циркуляции ценностных потоков материального и духовного характера. Процесс порождения и развития смыслового поля связан с непрерывным потреблением информации, ресурсов, текстов, идей и т. П. Подобным образом осуществляется выбор знаковосимволических форм культуры.

5. Мир-системный подход. По мнению И. Валлерстайна, первоначально главным эквивалентом обменных и перераспределительных отношений в мире являлись деньги, «размещенные в банках», которые «были затем вновь направлены в третий мир и социалистические страны (даже нефтепроизводящие) в виде государственных займов» [Валлерстайн, 2001, с. 162]. Замещение источников прибыли имело направления от производственной сферы к финансовой и наоборот. Создавались предпосылки к массовому потреблению предметов роскоши, что провоцировало падение темпов роста в странах третьего мира. Эта тенденция складывалась на фоне истощения финансовых и социальных резервов.

Капиталистическая мир-система, сформированная в XVI веке, представляла собой совокупность миро-хозяйств [Валлерстайн, 2004, с. 50], основанная на разделении труда. Отношения между ними выстраивались по принципу «центр - периферия». В процессе преобразования общества, происходит нарастание противоречий в обменных отношениях в связи с замещением существующих интересов и потребностей миро-хозяйственных систем.

Кризисные явления в культуре постепенно создавали предпосылки роста конфликтогенности в мире. Устоявшиеся формы и принципы коммуникации вызывали негативную реакцию значительной части общества на сложившиеся диспропорциональные структуры отношений.

\section{Язык культуры и преобразование структуры символического обмена}

В условиях многомерности информационного пространства у коммуникантов возникает интерес к «другой», «иной» для них культуре, способной вовлекать их в новый дискурс. Данный процесс дает начало диалоговой коммуникации и преобразованию структуры символического обмена. Интерес к исследованию символов и знаков, с помощью которых рождается смысл коммуникации, приводит к пониманию пространства потребления и пространства производства медиаобразов.

В мировой культуре глобальные культурные образцы и стили жизни, пропагандируемые через искусство рекламы и СМИ, соединяются с локальными традициями и ценностями. В массовой культуре большинства стран доминируют культурные коды, доступные для понимания массовой аудитории. Наслаиваясь на национальную систему ценности, они приобретают гибридные формы. В то же время это - акт самовыражения и идентификации культуры, позволяющей раскрывать новые грани искусства.

Потребительское отношение к продуктам массовой культуры происходит на фоне трансформации представления о реальности. Сегодня культура все более абстрагирована от исторических и географических условий. Она реализует себя в медиапространстве электронных коммуникаций, в котором преобладают аудиовизуальные гипертексты. Подобная теоретическая модель является ярчайшим примером многоаспектности процессов глобализации, в контексте которых осуществляется преобразование культурных практик обмена. Особенностью мировой культуры является также ее полимодальность и склонность к объединению существующих знаковых систем.

Из сказанного вытекает понимание того, каким образом создается язык культуры. Фактически, опираясь на идеи Ж. Бодрийяра, культурно-символический обмен приобрета- 
ет форму игры со знаками и смыслами. Г. Маркузе в своей работе «Одномерный человек» отмечал, что понятие «потребление» не воспринимается в качестве удовлетворения потребностей, так как замещается «детерминацией ложных потребностей» посредством вовлеченности в систему потребления, навязанную СМИ [Маркузе, 1994, с. 6]. Производители медиаобразов в виртуальном пространстве создают ситуацию потребности в них, а их потребитель отвечает взаимностью, устанавливая ценностную стоимость продукту в том или ином эквиваленте. Это сказывается на «симметричности интенсивностей обмена» с учетом пространственно-временных параметров [Моль, 1973, с. 93].

Иначе говоря, главным вопросом становится возможность сохранения ценностносмыслового содержания культурных образов в условиях симуляции отношений. Виртуальная реальность не представляет возможности применять привычные практики коммуникации. Пребывая в ней, человек потенциально становится распространителем псевдообразов. Возникает прецедент фрагментарного потребления информации. В то же время информация не переходит в форму знаний, т. е. не происходит куммуляции ценностей и норм, являющихся основным фундаментов традиций. Без процессов данного характера, нельзя говорить о репрезентации социальной памяти, служащей связующим мостом между поколениями. Как пишет А. Моль, «человек усваивает культуру из социального окружения, которое отчасти воспитывает ее в нем, отчасти же его ею пропитывает» [Моль, 1973, с. 47]. Обменные отношения как многогранный процесс, ориентированный на удовлетворение интересов и потребностей людей, позволяют проанализировать причины культурной трансформации и наметить основные тенденции развития человечества.

Современная культура состоит из противоречий. В постмодернистском обществе мы находимся в поисках тотального эффекта, абстрагируясь от понимания значения [Маклюэн, 2014, с. 32]. Тотальность происходящих изменений, охватывающих человечество, предполагает столкновение с фрагментарными процедурами в культурных практиках. Помимо этого, развитие массовой культуры связано с мифологизацией.

\section{Миф и коммуникативные матрицы обмена}

Порождение мифов подразумевает циркуляцию знаков, наделенных неким конкретным содержанием. Р. Барт определяет миф как «способ обозначения» [Барт, 2008, с. 265]. Соответственно, понимание мифа связано с формирование пространства дискурсов, которое воспринимается как «значимая единица» [Барт, 2008, с. 267]. Однако миф не есть первичная знаковая реальность. Он есть означающее. В этом видится возможность непрерывной трансформации и симуляции знаковых форм, не имеющих четкую структуру. Данное качество свидетельствует о функционировании коммуникативных матриц на базе обмена знаками и символами, важными с позиции той или иной реальности. Это пространство материальная основа любых культурных практик. Оно представляет собой «целенаправленные, повторяющиеся, программируемые последовательности обменов и взаимодействий между физически разъединенными позициями, которые занимают социальные акторы в экономических, политических и символических структурах» [Кастельс, 2000, с. 385]. Благодаря пространству потоков формируется представление о таких вещах, как власть, статус, престиж, богатство, роскошь, идеология, укорененных в культурных кодах. Соответственно мы говорим об образе жизни, о статусе, о престиже, об унифицированности символов, применяемых в обменных коммуникациях.

Связь между различными пространствами потоков обеспечивается за счет управленческих центров. В период становления массового общества, появления средств массовой коммуникации и рекламы, культурные образцы приобретают экспрессивность выражения посредством языка. Их закрепление реализуется благодаря развитию имиджевых и управленческих технологий. На этой основе зиждется наука, искусство, экономика, политика, культура. Все формы коммуникации в информационном обществе предполагают не четкую структуру взаимоотношений знаковости, а управление процессами симуляции знаками. 
Символы репутации и престижа, включенные в поле массмедиа, позволяют изменять культурное поле. Обращаясь к символическому полю средств языковых выражений, они закрепляются в массовом сознании через демонстрацию стилей жизни. Ценность в мире потребления знаков будет зависеть от суммарной стоимости самого идейного продукта [Моль, 1973, с. 96]. Чем больше идей будет сосуществовать в культурном поле имиджевых практик, тем многообразней будет коммуникационная матрица обменов.

А. Моль указывает на то, что современный человек существует в двух мирах: мире вещей и мире знаков [Моль, 1973, с. 87]. Мир знаков приобретает стоимостный характер в результате их массового распространения и значимости с точки зрения их создателя. Все это отражается на культуре как совокупности интеллектуальных элементов [Моль, 1973, с. 83] и порождает трансформацию ценностей и традиций. В целом стоит отметить, что по большей части в сетевом пространстве информация передается посредством разных каналов коммуникации: символьных, иконических, художественных и технических. При этом применяются аудиальный, визуальный, вербальный и невербальный коды. Знаковым репрезентатом выступает семиотический образ, эквивалент. Он появляется в результате созерцания внешних объектов, создающих связь между внутренним ментальным пространством и внешним миров коммуникации.

\section{Имиджевые константы в поле дискурсивных практик обмена}

Символический обмен как неотъемлемая составляющая коммуникации является весомым фактором дифференциации индивидов в структуре взаимоотношений. То, какое место займет индивид в иерархии, зависит от актуальности для аудитории его культурных ценностей, психологических предпочтений и социального окружения. Эти критерии проявляются через использование языка как знаковой системы. С помощью языка формируется символическое поле, объединяющее в себе «...пространственное, временное и смысловое измерение», позволяющее преодолевать разрыв между реальным и виртуальным пространством коммуникации «...между моей зоной манипуляции и зоной манипуляции другого...» [Бергер, Лукман, 1995, с. 68].

В то же время Дж. Мид акцентирует внимание на то, что жизнь человека связана с формированием значений вещей [Мид, 1994, с. 216]. Реальность человека заключена в пространстве существованием потока значений в процесс взаимодействия с другими. Человек выделяет себя в окружающей среде и формирует эту же среду посредством порождения ее знаковости.

«Вещь-знак» отсылает наше сознание к иному. Мэм, эмодзи - феномены виртуальной коммуникации. Они являются предметом культурно-символического обмена. Рождение смысла обменных отношений происходит на фоне переживания некоего абстрактного нечто в «социально воспринимаемый знакообраз» [Пелипенко, 2002, с. 10]. Значение не исчерпывается смыслом, но является семантической его компонентой, создающей ценностно-нормативную основу обмена.

Смысл как ценность, переживаемое значение, выражено в кодах [Пелипенко, 2002]. Транслируясь в обменных отношениях, он реализуется в культуре. Формирование виртуального пространства культуры происходит благодаря первичным знаниям человека о знаковых кодах культуры, на которые наслаивается опыт общения и коммуникации не только в первичных группах социализации, но и в процессе существования человека в обществе.

Современное виртуальное пространство является сосредоточением процесса смыслогенеза, приводящее к трансформации культурного пространства. Фундаментальное противоречие бытия человека в культуре заключается между континуальным и дискретным характером мышления. Нормативный контекст, объединяющий имиджевые характеристики коммуникации, накладывается на уже устоявшиеся нормы и традиции того или иного общества. Символическое ядро взаимоотношений представлено информационными технологиями. Благодаря массмедиа происходит не только активное внедрение имиджевых 
констант в поле дискурсивных практик обмена, но и манипуляция ими в зависимости от целей и мотивов коммуникатора. Они осуществляются с помощью социально и личностно ориентированных технологий.

Ценности, нормы и социальное поведение людей сводятся к получению позитивных эмоций, связанных с наслаждением от потребления символов: «ссылка на норму... подразумевает совместное создание смыслового (коммуникативного, интерсубъективно доступного) отношения, устремленного к взаимопониманию и соответствующим действиям» [Шульга, 2012, с. 281]. Посредством языка, понятного человеку информационной эпохи и принятому для осуществления виртуальных коммуникаций, становится возможно понимание различий доступных знаковых систем и понятий. Благодаря им индивиды вступают в отношения и изменяют практику обмена. Взаимодействия приобретают эмоционально-экспрессивную окраску ввиду наличия возможности отклика на связь в виртуальном пространстве. Основными конструктивными принципами при этом становятся возмездность и замещение обмена символами. Это обеспечивает эффект коммуникации и достижение взаимопонимания между людьми.

В виртуальной среде существует множество знаковых систем, за которыми может скрываться различное смысловое наполнение. Наличие противоположной, отличной от нашего опыта и восприятия реальности обеспечивает духовную связь между контакторами. Индивиды, принимающие вызов виртуального пространства, восполняют дефицит интересующей и важной с точки зрения их социального опыта и познания информацию. Информация как основной ресурс информационного общества необходима не только как нечто привычное для повседневной жизни, но прежде всего как символическая основа обменных отношений. Они в свою очередь могут иметь различные формы и модальности своего воплощения.

Непрерывность и продолжительность культурного обмена определяет временные интервалы их существования на микро-, мезо- и макроуровне. Они развертываются в пространстве и имеют социальное измерение. Например, обмен социальным опытом поколений конкретной культурной общности обладает огромной временной протяженностью. Он включает передачу знаний и традиций приветствия, нравов, обычаев, правил общения индивидов. Для виртуальной реальности свойственны формы приветствия краткосрочного характера.

Солидарность в структуре обмена символами способствует укреплению и стабильному существованию системы коммуникации. В условиях прекращения действия принципа возмездности в обмене преобладающим становится цент-периферийное распределение потока информации и, как следствие, формирование символического поля манипуляции.

Информационное общество обладает достаточно важным и весомым преимуществом - интерес и потребность в многообразной информации. Одновременно это сказывается на стремлении порождать и распространять разнообразные образы, представляя реальность как мозаику. Возникает вопрос о создании качественной системы социальных институтов, отвечающих за управление и сохранение баланса между уровнем жизни и моделями потребление знаковых систем глобальной и локальной культуры. От этого зависит наполнение символического пространства обмена по принципу взаимной возмездности.

\section{Заключение}

Исходя из вышеизложенного, стоит отметить, что культурно-символический обмен представляет совокупность коммуникативных практик, функционирующих по принципу циркуляции ценностных потоков материального и духовного характера.

Процесс преобразования культурных практик обмена имеет исторический, пространственно-временной и социальных аспекты, находящие отражение в современном медиадискурсе.

Информационные преобразования привели к переменам в социальной, культурной, экономической и политической сферах бытия. Становясь участниками процессов инфор- 
матизации и компьютеризации, человечество открывает возможности к дальнейшей эволюции форм коммуникации. Сосуществуюя в условиях цифровизации медиапространства, возникает угроза замещения реальных образов псевдообразами. По словам Ж. Бодрийяра, человек имеет дело с процессом симуляции, порождающей симулякров не имеющих смыслового ядра.

В то же время, данные процессы создают предпосылки для неоднозначных тенденций в культуре, выраженных в симуляции потребления имиджевых констант, фрагментации и мифологизации информационного пространства.

Перспективным становится рассмотрение культурно-символического обмена как формы конструирования новой реальности культуры в русле культурфилософского подхода. Видится возможность исследовать совершенно новые формы человеческой коммуникации, формирующиеся в виртуальной среде.

Трансформация культуры порождает интерес к теме культурно-символического обмена, связанного с процессами воспроизводства и реализации творческого потенциала человека в социальной практике.

\section{Список литературы}

1. Барт Р. 2008. Мифологии. М., Академический Проект, 351 с.

2. Бергер П., Лукман Т. 1995. Социальное конструирование реальности. Пер. с англ. М., Academia-центр, Медиум, 334 с.

3. Бодрийяр Ж. 2000. Америка. Пер. с фр. М., Владимир Даль, 204 с. (Baudrillard J. 1986. Amérique. Paris, 251 p.).

4. Бодрийяр Ж. 2000. Символический обмен и смерть. Пер. с фр. М., Добросвет, 387 с. (Baudrillard J. 1976. Échange symbolique et mort, Paris, 387 p.).

5. Валлерстайн И. 2001. Анализ мировых систем и ситуация в современном мире. Пер. с англ. СПб: Изд-во «Университетская книга». 416 с. (Wallerstein, I. 1974. The Modern World-System. New York, 440 p.).

6. Валлерстайн И. 2004. Конец знакомого мира: Социология XXI века. Пер. с англ. М., Логос, 368 с. (Wallerstein, I. The end of the world as we know it: Social Science for the Twenty-First Century, London, 368 p.).

7. Гутнер Г.Б. 2012. Смысл в контексте рациональной коммуникации. В кн.: Коммуникативная рациональность и социальные коммуникации 2012: коллективная монография. Под ред. И.Т. Касавина, В.Н. Поруса. Москва, Альфа-М: 421-431.

8. Кастельс М. 2000. Информационная эпоха: экономика, общество, культура. Пер. с англ. М.: ГУ ВШЭ, 608 с. (Castels M. 1996. Information age: economy, society, culture. Oxford, 556 p.).

9. Леви-Стросс К. 2001. Структурная антропология. Пер. с фр. М., Эксмо-Пресс, 512 с. (Levi-Strauss K. 963. Anthropologie structurelle. New York, 512 p.).

10. Маклюэн Г.М. 2014. Понимание медиа: Внешние расширения человека. Пер. с англ. М.: КАНОН-пресс-Ц, Кучково поле, 464 с. (McLuhan G. M. 1994. Understanding media: External human extensions, London and New York, 464 p.).

11. Маркузе Г. 1994. Одномерный человек. Исследование идеологии развитого индустриального общества. Пер. с англ. M.: REFL-book, 368 с. (Marcuse G. 1966. One-dimensional man. Research on the ideology of a developed industrial society. Boston, 260 p.).

12. Мид Дж. 1994. От жеста к символу. В кн.: Американская социологическая мысль 1994. Под ред. В.И. Добренькова. Москва: МГУ: 213-221. (Mead G. From Gesture to Symbol. Mead G. Mind, Self and Society. Chicago, 1934. 66-76 p.).

13. Моль А. 1973. Социодинамика культуры. Пер с фр. М., Прогресс, 407 с. (Abraham А. Moles.1971. Sociodynamique de la culture, Paris. 342 p.).

14. Парсонс Т. 1998. Система современных обществ. М., Аспект Пресс, 270 с. (Parsons T. 1971. The system of modern societies. New York, 270 p.).

15. Пелипенко А.А. 2002. Генезис смыслового пространства и онтология культуры. Человек, 2: 6-21.

16. Шульга Е.Н. 2012. Символический интеракционизм и рациональность. В кн.: Коммуникативная рациональность и социальные коммуникации 2012: коллективная монография. Под ред. И.Т. Касавина, В.Н. Поруса. Москва, Альфа-М.: 275-287. 


\section{Reference}

1. Bart R. 2008. Mifologii. [Mythologie]. M., Akademicheskii Proekt, 351 p.

2. Berger P., Lukman T. 1995. Sotsial'noe konstruirovanie real'nosti. [The Social Construction of Reality. A Treatise on Sociology of Knowledge]. M., Academia-centr, Medium, 334 p.

3. Bodrijyar Zh. 2000. Amerika. [Amerique]. M., Vladimir Dal', 204 p. (Baudrillard J. 1986. Amérique. Paris, 251 p.).

4. Bodriiyar Zh. 2000. Simvolicheskii obmen i smert'. [L`echange simbolique et la mortm]. M., Dobrosvet, 387 p. (Baudrillard J. 1976. Échange symbolique et mort, Paris, 387 p.).

5. Vallerstain I. 2001. Analiz mirovykh sistem i situatsiya v sovremennom mire. [The Modern World-System]. SPb., Publ. Universitetskaya kniga. 416 p. (Wallerstein, I. 1974. The Modern WorldSystem. New York, 440 p.).

6. Vallerstain I. 2004. Konets znakomogo mira: Sotsiologiya XXI veka [The End of the World as We Know It. Social Science for the Twenty-First Century]. M., Logos, 368 p. (Wallerstein, I. The end of the world as we know it: Social Science for the Twenty-First Century, London, 368 p.).

7. Gutner G.B. 2012. Smysl v kontekste racional'noj kommunikacii. [Meaning in the context of rational communication]. In: Kommunikativnaja racional'nost' i social'nye kommunikacii 2012. [Communicative rationality and social communications 2012]. Ed.: I.T. Kasavin, V.N. Porus. Moskva, Al'fa-M: 421-431.

8. Kastel's M. 2000. Informatsionnaya epokha: ekonomika, obshchestvo, kul'tura. [The Information Age: Economy, Society and Culture]. M., GU VshE, 608 p. (Castels M. 1996. Information age: economy, society, culture. Oxford, 556 p.).

9. Levi-Stross K. 2001. Strukturnaya antropologiya. [Anthropologie structurale]. M.: EksmoPress, 512 p. (Levi-Strauss K. 963. Anthropologie structurelle. New York, 512 p.).

10. Maklyuen G.M. 2014. Ponimanie media: Vneshnie rasshireniya cheloveka. [Understanding media: the extensions of man]. M.: KANON-press-C, Kuchkovo pole, 464 p. (McLuhan G. M. 1994. Understanding media: External human extensions, London and New York, 464 p.).

11. Markuze G. 1994. Odnomernyi chelovek. Issledovanie ideologii razvitogo industrial'nogo obshchestva [One-Dimensional Man. Studies in the Ideology of Advanced Industrial Society]. M., REFLbook, 368 p. (Marcuse G. 1966. One-dimensional man. Research on the ideology of a developed industrial society. Boston, 260 p.).

12. Mid Dzh. 1994. Ot zhesta $\mathrm{k}$ simvolu. [From gesture to symbol]. In: Amerikanskaja sociologicheskaja mysl' 1994. [American sociological thought, 1994.] Ed.: V.I. Dobren'kova. Moskva, MGU: 213-221. (Mead G. From Gesture to Symbol. Mead G. Mind, Self and Society. Chicago, 1934. $66-76 \mathrm{p}$.$) .$

13. Mol' A. 1973. Sotsiodinamika kul'tury [Sociodynamique de la culture]. M.: Progress, 407 p. (Abraham A. Moles.1971. Sociodynamique de la culture, Paris. 342 p.).

14. Parsons T. 1998. Sistema sovremennykh obshchestv [The System of Modern Societies]. M., Aspekt Press, $270 \mathrm{p}$.

15. Pelipenko A.A. 2002. Genezis smyslovogo prostranstva i ontologiya kul'tury [Genesis of semantic space and ontology of culture]. Chelovek, 2: 6-21. (Parsons T. 1971. The system of modern societies. New York, 270 p.).

16. Shul'ga E.N. 2012. Simvolicheskij interakcionizm i racional'nost'. [Symbolic interactionism and rationality]. In: Kommunikativnaja racional'nost' i social'nye kommunikacii 2012. [Communicative rationality and social communications 2012]. Ed.: I.T. Kasavina, V.N. Porusa. Moskva, Al'fa-M.: 275-287.

\section{ИНФОРМАЦИЯ ОБ АВТОРЕ}

Серостанова Оксана Борисовна, ассистент кафедры журналистики и медиакоммуникаций Луганского национального университета имени Tараса Шевченко, г. Луганск, Украина

\section{INFORMATION ABOUT THE AUTHOR}

Oksana B. Serostanova, assistant of the Department of journalism and media communications of the Taras Shevchenko national University, Luhansk, Ukraine 